\title{
Mensuração do complexo agroindustrial no mundo: comparativo entre países
}

\author{
Measurement of the agro-industrial complex in the world: \\ comparative between countries
}

Umberto Antonio Sesso Filho ${ }^{1}$ (D), Lucas Trindade Borges ${ }^{1}$ (D), Patrícia Pompermayer Sesso ${ }^{1}$ (i), Paulo Rogério Alves Brene ${ }^{1}$ [D, Emerson Guzzi Zuan Esteves ${ }^{1}$ (])

1Programa de Pós-graduação em Economia Regional, Universidade Estadual de Londrina (UEL), Londrina (PR), Brasil. E-mails: umasesso@uel.br; borgesbr89@gmail.com; papomper2004@yahoo.com.br; paulobrene@uenp.edu.br; emerson.esteves@uel.br

Como citar: Sesso Filho, U. A., Borges, L. T., Pompermayer Sesso, P., Brene, P. R. A., \& Esteves, E. G. Z. (2022). Mensuração do complexo agroindustrial no mundo: comparativo entre países. Revista de Economia e Sociologia Rural, 60(1), e235345. https://doi.org/10.1590/1806-9479.2021.235345

\begin{abstract}
Resumo: Os objetivos do estudo foram estimar o Produto Interno Bruto (PIB) do Agronegócio para 63 países e Restante do mundo no período de 1995 a 2015 e analisar comparativamente os resultados e relações com o Índice de Desenvolvimento Humano (IDH). A metodologia utiliza a matriz insumo-produto e as fontes dos dados foram a Organização para a Cooperação e Desenvolvimento Econômico (OCDE) e Organização das Nações Unidas (ONU). Os resultados mostraram que a participação do agronegócio no PIB mundial diminuiu de 18,4\% para 15,2\% e a maior parte dos países (59 em 63) apresentou a mesma tendência no período simultaneamente com aumento do Índice de Desenvolvimento Humano. Os maiores valores absolutos do PIB do agronegócio em 2015 correspondem a China (2496 Bilhões US\$), Estados Unidos (1395 Bilhões US\$), Índia (637 Bilhões US\$), Japão (414 Bilhões US\$) e Brasil (316 Bilhões US\$). O Brasil passou da oitava para a quinta posição do PIB do agronegócio no período e a participação na economia diminuiu de 24,4\% para 19\%. Países com maiores valores de IDH apresentaram maior participação da indústria e serviços na composição do PIB do agronegócio.
\end{abstract}

Palavras-chave: agronegócio, insumo-produto, complexo agroindustrial, desenvolvimento econômico.

Abstract: The objectives of the study were to estimate the gross domestic product (GDP) of agribusiness for 63 countries and the Rest of the world in the period from 1995 to 2015 and to analyze comparatively the results and relations with the human development index (HDI). The methodology uses the input-output matrix and the data sources were the Organization for Economic Cooperation and Development (OECD) and the United Nations (UN). The results showed that the share of agribusiness in world GDP decreased from $18.4 \%$ to $15.2 \%$ and most countries (59 out of 63 ) showed the same trend in the period simultaneously with an increase in the HDI. The highest absolute values of agribusiness GDP in 2015 correspond to China (US\$ 2.496 trillion), United States (US\$ 1.395 trillion), India (US\$ 637 billion), Japan (US\$ 414 billion), and Brazil (US\$ 316 billion). Brazil went from the eighth to the fifth position of the agribusiness GDP in the period and the participation in the economy decreased from $24.4 \%$ to $19 \%$. Countries with higher HDI values showed greater participation by industry and services in the composition of agribusiness GDP.

Keywords: agribusiness, input-output, agro-industrial complex, economic development.

\section{Introdução}

O agronegócio corresponde ao somatório das atividades diretas ou relacionadas à produção e distribuição de alimentos e fibras, sendo dividido em quatro agregados: insumos agrícolas, agropecuária, processamento e distribuição (Davis \& Goldberg, 1957). Segundo Delgado et al. (1998), a importância do agronegócio para o crescimento econômico de um país reside na sua capacidade de fornecer matéria-prima para a indústria, alimentos para a população, poupança para investimento na indústria, ampliação dos mercados para produção industrial e receita mediante exportação. De Janvry (2010) afirma que um novo paradigma começou a emergir 
sobre o papel da agricultura para o desenvolvimento e a adoção de uma nova agenda mais ampla. Byerlee et al. (2009) afirmam que a agricultura foi vista no passado como fonte de contribuições que ajudaram a induzir crescimento industrial e uma transformação estrutural da economia. No entanto, a globalização, cadeias de valor, inovações tecnológicas e institucionais e restrições ambientais modificaram rapidamente o contexto e o papel da agricultura. Os autores afirmam que um novo paradigma é necessário para o reconhecimento das múltiplas funções da agricultura para o desenvolvimento nesse contexto emergente: impulso ao crescimento econômico, redução da pobreza, diminuição das disparidades de renda, garantia de segurança alimentar e preservação do meio ambiente.

O papel do agronegócio na economia se modifica com o desenvolvimento econômico dos países. A principal tarefa da agricultura de países pobres é fornecer alimentos e fibras a baixo custo para a população e para a indústria. Nesses países, o setor agroindustrial e de serviços são pouco desenvolvidos, pois a demanda por alimentos e fibras é pouco exigente e o governo dá prioridade ao investimento na indústria de base. Nos países em desenvolvimento, a agropecuária é responsável por aumentar a renda das famílias rurais e reduzir a pobreza. Em países desenvolvidos, o setor agropecuário apresenta diversas funções. Além de fornecer alimentos e fibras para a população, ele cumpre um papel de proteção ambiental e ecológico. Os setores de processamento e distribuição são desenvolvidos, pois os consumidores exigem qualidade, conveniência e facilidades no uso dos produtos. O governo apoia o interesse dos produtores rurais e subsidia as atividades (Leones et al., 1994; Pingali, 2007). Além da transformação do papel do agronegócio na economia de acordo com o desenvolvimento econômico, a transformação estrutural em que a participação da agricultura no emprego e no PIB total dos países declina, à medida que a renda per capita aumenta, apresenta alta regularidade (Byerlee et al., 2009).

A estrutura de agregação de valor (renda) das partes do complexo agroindustrial se modifica com o desenvolvimento econômico e advento das novas tecnologias, as quais são adotadas em toda a cadeia de produção, processamento e distribuição. Quanto mais rápida a identificação de fatores importantes para a industrialização, mais rápida a garantia de competitividade no mercado. A industrialização deve estimular a geração de novos empregos, reduzir a desigualdade salarial, tornar os alimentos mais acessíveis, melhorar a qualidade do alimento e a segurança alimentar, aumentar a variedade de produtos e proteger o meio ambiente. De forma relativamente rápida e intensa, a década de 1990 trouxe o desenvolvimento da agroindústria para diversas economias de baixa e média renda (Reardon \& Barrett, 2000).

Considerando as modificações da participação do agronegócio na economia e da composição da renda dos agregados determinadas pelo desenvolvimento dos países, o presente estudo tem como objetivos dimensionar o Produto Interno Bruto do Agronegócio para 63 países e analisar comparativamente os resultados, evolução e relação com o Índice de Desenvolvimento Humano (IDH). O dimensionamento do PIB do agronegócio será baseado na divisão proposta por Davis \& Goldberg (1957) em quatro partes ou agregados: insumos, agropecuária, agroindústria e serviços. A metodologia foi desenvolvida por Furtuoso et al. (1998) e aplicada pelos autores para o Brasil, a qual baseia-se nos dados da matriz de insumo-produto disponibilizados pela OECD (Organisation for Economic Co-operation and Development, 2019).

O estudo preenche lacunas no tema de pesquisa com o dimensionamento do agronegócio de 63 países no período mais recente, 1995-2015. Os resultados tornam possível a comparação da estrutura do agronegócio entre as diferentes regiões, evolução e relações com o Índice de Desenvolvimento Humano (IDH). O texto está dividido em cinco seções incluindo a Introdução. A segunda seção traz estudos recentes sobre o tema. A terceira trata da metodologia e fontes dos dados. A quarta seção apresenta os resultados e discussão e a quinta as conclusões. 


\section{Dimensionamento do agronegócio e desenvolvimento}

O estudo inicial de Furtuoso et al. (1998) deu origem a uma série de trabalhos sobre o dimensionamento do agronegócio com a aplicação da metodologia para estados e países utilizando principalmente as variáveis renda (Produto Interno Bruto) e emprego. Os diversos estudos já realizados sobre o tema se referem ao Brasil e suas unidades da federação, províncias da China e países.

A metodologia de dimensionamento do agronegócio foi aplicada para os estados brasileiros. O Centro de Estudos Avançados em Economia Aplicada estima o Produto Interno Bruto do agronegócio do Brasil, estados de São Paulo e Minas Gerais e cadeias produtivas de forma sistemática. Para o Brasil, os dados iniciam em 1995 (Centro de Estudos Avançados em Economia Aplicada, 2019).

Guilhoto et al. (2007) realizaram o dimensionamento do agronegócio da Bahia nos anos de 1990 e 2005. A cadeia agroindustrial foi dividida em agregados. As principais conclusões foram que $27,7 \%$ do PIB nacional e $25,4 \%$ do PIB baiano são gerados pelo agronegócio.

O estado de Minas Gerais possui dois estudos de dimensionamento do seu agronegócio. Cruz et al. (2009) realizaram o dimensionamento do agronegócio deste estado no ano de 1999. Os resultados mostraram que o agronegócio mineiro gerou rendas equivalentes a $29,76 \%$ do PIB do estado e 9,6\% do PIB do agronegócio nacional. Os setores fornecedores de insumos para a agropecuária participaram com 20,73\% do PIB do agronegócio de Minas Gerais, a agropecuária com $27,53 \%$ e as atividades de processamento, industrialização e distribuição com 51,75\%. Gilio et al. (2016) estimaram o Produto Interno Bruto (PIB) do agronegócio do estado de Minas Gerais no período de 2004 a 2015. O PIB do agronegócio do estado foi de 184,2 bilhões de reais no ano de 2015 e existia alta relação entre o agronegócio e o PIB total do estado e do crescimento em importância dos segmentos agroindustriais em relação à produção primária. Os autores verificaram a manutenção da elevada participação de cadeias produtivas tradicionais, como as relacionadas ao café e ao leite, que se modernizaram nas últimas décadas e se mantiveram competitivas.

Araújo Neto \& Costa (2005) realizaram o cálculo do PIB do agronegócio de Pernambuco. O estudo conceituou e caracterizou de modo setorial o complexo agroindustrial (CAl). Os principais resultados indicam que o PIB do agronegócio de Pernambuco representava 21,2\% do PIB total do estado.

A Região Sul do Brasil e seus estados foram tema de três estudos relacionados ao dimensionamento do agronegócio e os resultados são convergentes. Sesso Filho et al. (2011) estimaram o Produto Interno Bruto (PIB) do agronegócio da Região Sul em R $\$ 125$ bilhões no ano de 2004. Isto representava $27 \%$ do total do PIB do agronegócio brasileiro ( $R \$ 460$ bilhões) e $39 \%$ do PIB total regional ( $\mathrm{R} \$ 322$ bilhões). O estado com maior participação no agronegócio da região foi o Rio Grande do Sul, seguido do Paraná e de Santa Catarina. A geração de empregos a partir do agronegócio correspondeu a um terço da força de trabalho da Região Sul. Nunes \& Parré (2013) dimensionaram o agronegócio do Paraná em 2007. A participação do agronegócio no PIB paranaense era de cerca de $30 \%$. A agroindústria apresentava alta participação no agronegócio paranaense, o que mostrou que o agronegócio do estado do Paraná pode ser considerado industrializado. Finamore \& Montoya (2003) dimensionaram o agronegócio do Rio Grande do Sul no ano de 1998. Os resultados mostraram que o agronegócio representava $36,67 \%$ do PIB do estado. Além disso, os autores mostraram que $29,31 \%$ dos impostos indiretos líquidos provêm da agroindústria e que o agronegócio do Rio Grande do Sul empregava 47,68\% do total de trabalhadores. 
Guilhoto et al. (2011) dimensionaram as cadeias produtivas de base familiar das unidades da federação nos anos de 1995 a 2005. Os resultados mostraram que 10\% do PIB nacional pertencem às cadeias produtivas da agricultura familiar, o valor representa aproximadamente um terço do total das cadeias produtivas agropecuárias. A Região Sudeste era responsável por $55 \%$ do PIB nacional e $24 \%$ do PIB da agricultura familiar. Os autores afirmaram que a agricultura familiar se concentra no sul do Brasil.

Silva et al. (2015) avaliaram a dimensão econômica do agronegócio paulista, tomando como referência o tamanho do seu PIB e sua participação no agregado nacional, bem como o número de pessoas empregadas no setor. Os resultados mostraram que em 2013 o agronegócio paulista gerou um PIB de $R \$ 213,1$ bilhões, o que representou 19\% do agronegócio nacional e $15 \%$ do PIB total do estado. Em termos de mão de obra, o agronegócio responde por 17\% do emprego formal da economia paulista.

Sesso Filho et al. (2019a) dimensionaram o complexo agroindustrial das unidades da federação considerando o Produto Interno Bruto, empregos e impostos gerados em quatro agregados (insumos, agropecuária, indústria e serviços). A análise foi feita a partir das matrizes de insumoproduto estaduais do ano de 2008. Os resultados mostraram que os estados do Mato Grosso, Mato Grosso do Sul, Goiás e Rondônia possuíam maior importância do Agronegócio com no mínimo $40 \%$ do Produto Interno Bruto estadual, 50\% dos empregos e $41 \%$ dos impostos indiretos líquidos. A produtividade do trabalho no Agronegócio dos estados do Norte e Nordeste é aproximadamente metade da produtividade do Sudeste/Sul do Brasil, o que mostra potencial de investimentos em tecnologia, capital e qualificação profissional. A indústria sofre a maior parte da tributação, variando entre $9 \%$ e $33 \%$ e poderia beneficiar-se de desoneração.

A maior parte dos estudos sobre dimensionamento do agronegócio do Brasil e unidades da federação envolve a estimativa dos valores absolutos e relativos do complexo agroindustrial na economia em termos de Produto Interno Bruto, portanto replicam a metodologia proposta em Furtuoso et al. (1998). Guilhoto et al. (2011) trazem a inovação da desagregação do agronegócio de base familiar no Brasil e o estudo de Sesso Filho et al. (2019a) abrange todas as unidades da federação.

Os estudos de dimensionamento do agronegócio envolvendo diversos países utilizam dados da Cooperação e Desenvolvimento Econômico (OCDE) ou World Input Output Database (WIOD). Os bancos de dados apresentam as matrizes de insumo-produto e variáveis como emprego, renda e emissões atmosféricas.

Schluter et al. (1986) dimensionaram o emprego e a renda gerados pelo Sistema de Alimentação e Fibras (SAF) dos EUA. Os resultados para o ano de 1984 mostraram que o SAF gerou $18 \%$ do PIB do país e empregou 21 milhões de trabalhadores em tempo integral, o que correspondia aproximadamente a $18,5 \%$ dos empregos totais. Os autores afirmaram que houve um declínio da participação do sistema ao longo do tempo, se comparados com dados da década anterior, na qual o SAF representava $20,5 \%$ do PIB total e $21 \%$ do total de empregos.

Yan et al. (2011) dimensionaram o agronegócio dos países da OECD com dados de 1997 e 2002. Além disso, realizaram os cálculos para vinte e nove províncias chinesas. Os resultados obtidos indicaram que a diminuição da participação do PIB do agronegócio no PIB total dos respectivos países e províncias chinesas tinha correlação positiva com o aumento da renda per capita, assim como a participação dos setores de indústria e de serviços no PIB do agronegócio. Os autores aplicaram uma metodologia modificada de Furtuoso et al. (1998) de dimensionamento do agronegócio a outros países e tiveram como um dos objetivos relacionar a participação do agronegócio na economia e renda per capita, no entanto o intervalo de tempo foi relativamente curto para atingir tal objetivo. 
Sesso Filho et al. (2019b) estimaram a geração de renda, emprego e emissões atmosféricas do agronegócio para quarenta países e o resto do mundo dividido em insumos, produção agrícola, indústria e serviços. Utilizaram-se matrizes de insumo-produto nacionais no ano de 2009 do World Input Output Database (WIOD). Os resultados mostraram que o Agronegócio participava com $15 \%$ do total da renda mundial e gerava 926 milhões de empregos nos quarenta países (45\% do total). Os países com maior participação do agronegócio no Produto Interno Bruto e empregos, respectivamente, foram Indonésia (36\% e 57\%), Turquia (33\% e 45\%), Índia (33\% e $68 \%$ ), Romênia ( $27 \%$ e $44 \%$ ) e China ( $26 \%$ e $52 \%$ ). A participação do agronegócio em emissões de dióxido de carbono equivalente no mundo era de $24 \%$ e os países com maiores valores de participação do agronegócio em emissões de dióxido de carbono total em seu país foram Brasil (66\%), Indonésia (43\%), Irlanda (42\%), França e Estônia (36\%).

As lacunas das pesquisas sobre o tema de dimensionamento do agronegócio dos países e desenvolvimento são realizar comparações entre países e relacionar a participação do PIB do agronegócio e de seus agregados com indicadores de desenvolvimento. Para analisar os resultados do estudo proposto, é importante analisar o papel do agronegócio no desenvolvimento dentro de um novo contexto de cadeias produtivas, globalização, rápidos avanços tecnológicos e institucionais e questões ambientais.

Segundo Byerlee et al. (2009), os governos negligenciaram as funções da agricultura no desenvolvimento ao longo do tempo, assim, o crescimento da agricultura foi reduzido. 0 resultado é que $75 \%$ da pobreza mundial é rural, disparidades setoriais explodiram, a insegurança alimentar retornou e a degradação ambiental é generalizada. Teóricos clássicos, liderados por Lewis (1954), viam o desenvolvimento econômico como um processo de crescimento no qual ocorria a realocação de fatores de produção de um setor agrícola caracterizado por baixa produtividade e utilização de tecnologia tradicional para um setor industrial moderno e com maior produtividade. No entanto, na década de 1960, uma revisão importante no pensamento sobre desenvolvimento defendeu um papel central para a agricultura como motor de crescimento, especialmente nos estágios iniciais da industrialização. Essa visão do papel principal da agricultura estimulada em grande parte pelos países emergentes na Ásia foi fundada em duas contribuições principais. Primeiro, estudiosos como Schultz (1964) e Hayami \& Ruttan (1985) mostraram que a agricultura tradicional poderia ser transformada rapidamente em um setor moderno através da adoção de tecnologia, dando assim uma grande contribuição para o crescimento da economia. Em segundo lugar, os economistas explicitamente identificaram as fortes ligações de crescimento e os efeitos multiplicadores do crescimento agrícola para os setores não agrícolas.

Dentro do contexto do novo papel da agricultura no desenvolvimento apresentado por Byerlee et al. (2009), Srinivas \& Vieira Filho (2017) afirmam que ambos os modelos de excedente de trabalho (Lewis, 1954) e inovação induzida (Hayami \& Ruttan, 1985) reconhecem que a demanda desempenha um papel vital na formação da agricultura e da manufatura. O verdadeiro desafio para as teorias de desenvolvimento é perceber que a estratégia de exportação de produtos industriais que beneficiou tanto a Coreia do Sul, Japão ou China não é uma trajetória de crescimento inevitável, mas uma escolha entre produção industrial e exportações agrícolas. Embora os ganhos com a indústria voltada para a exportação mereçam atenção, sabemos que as ligações entre a agricultura e a indústria têm sido pouco estudadas. Os setores de máquinas e equipamentos agrícolas, como exemplos, podem atuar como conexões entre o setor agropecuário tradicionalmente visto como primário/subsistência e um setor secundário/ capitalista ou mais produtivo. Na realidade, fornecedores e serviços alimentam ambos os 
setores com substanciais transbordamentos de aprendizagem que cruzam a agricultura e manufatura e, portanto, instituições rurais e urbanas (.

Existem diferenças importantes da produtividade da terra e do trabalho entre os países desenvolvidos e em desenvolvimento, porém a lacuna está diminuindo ao longo do tempo. A maior parte do ganho de produtividade nos países em desenvolvimento provém do aumento do uso de fertilizantes, máquinas, energia e irrigação. De forma geral, nos países de alta renda, a taxa de crescimento da produtividade total dos fatores é estável com maior aumento da produtividade do trabalho que dos outros fatores. Nos países em desenvolvimento, a taxa de crescimento da produtividade total dos fatores aumentou, principalmente no Brasil e China, mas na África Subsaariana a taxa não aumentou (Fuglie et al., 2012).

Brigatte \& Teixeira (2010) comprovaram as afirmações de Fuglie et al., (2012) para a agropecuária do Brasil em um estudo dentro do período de 1974 a 2005. Os resultados mostraram que investimentos em energia elétrica, pesquisa agrícola e armazenagem aumentaram o PIB agropecuário do Brasil a longo prazo, sendo o efeito exercido pela pesquisa agrícola o maior entre os observados. A melhoria da educação dos trabalhadores no campo exerceu impacto positivo sobre o produto agropecuário. Investimento em rodovias, ferrovias, portos e irrigação, além de crédito rural não mantém relação de longo prazo com o PIB da agropecuária. Além da adoção rápida de novas tecnologias, Luz (2014) afirma que a agricultura brasileira gera alto valor agregado, sendo maior que valor adicionado (VA) que a indústria por unidade monetária faturada. Enquanto a agricultura gera $\mathrm{R} \$ 0,57$ de VA para cada real de valor bruto da produção (VBP), a indústria gera $R \$ 0,33$. Os autores concluem que a agricultura brasileira é de alto valor agregado e pode contribuir muito com o crescimento do País. Além disso, a indústria é vítima de um alto consumo intermediário, resultado de políticas industriais equivocadas e ausência de políticas horizontais que poderiam contribuir para reduzir o custo industrial.

A metodologia proposta para o dimensionamento do agronegócio dos países está em consonância com a visão atual do papel do setor agropecuário no desenvolvimento, na qual as ligações entre a agropecuária e o restante dos setores da economia são levadas em consideração para analisar a contribuição do agronegócio para o desenvolvimento. A visão de cadeias produtivas da proposta metodológica de Furtuoso et al. (1998) utiliza dados das matrizes de insumo-produto de fluxos de bens e serviços entre o setor agropecuário e o restante da economia (ligações intersetoriais) para mapear o complexo agroindustrial e estimar o valor adicionado de seus agregados (insumos, agropecuária, indústria e serviços) mostrando as conexões entre as atividades rurais e urbanas.

As lacunas da pesquisa sobre o tema preenchidas pelo estudo proposto são o dimensionamento do agronegócio para 63 países para um período mais recente disponível, 1995-2015, realizar a análise comparativa dos resultados entre os países, avaliar a evolução do agronegócio no mundo e relações da estrutura de valor do agronegócio e participação na economia com o Índice de Desenvolvimento Humano (IDH).

\section{Metodologia}

\subsection{Fontes dos dados}

A base de dados elaborada pela OCDE - Organização para Cooperação e Desenvolvimento Econômico (Organisation for Economic Co-operation and Development, 2019) é a fonte das 
matrizes de insumo-produto de 63 países sendo 35 países membros, 28 não membros e o agregado Outros Países (Restante do mundo). Os dados mais antigos divulgados datam de 1995 e a última base de dados se refere ao ano de 2015. As matrizes mais recentes possuem 36 setores. Dados sobre Índice de Desenvolvimento Humano foram obtidos da UNDP - United Nations Development Programme (2019).

Os Quadros 1 e 2 mostram os setores produtivos e países do estudo, respectivamente. No Quadro 1, temos que os setores pertencentes ao agronegócio são (1) Agropecuária, (5) Alimentos, bebidas e tabaco, (6) Têxteis, vestuário, couro e produtos relacionados, (7) Madeira e produtos de madeira e cortiça e (8) Produtos de papel e impressão. O Quadro 2 apresenta os 63 países em análise, os quais representavam mais de $90 \%$ da renda mundial nos anos de 1995 e 2015. É importante lembrar que o agregado Outros Países representa o restante do mundo.

Quadro 1. Setores produtivos da economia para a matriz insumo-produto dos países.

\begin{tabular}{|c|c|c|c|}
\hline \multicolumn{4}{|c|}{ Setores da matriz de insumo-produto } \\
\hline 1 & Agropecuária, silvicultura e pesca & 19 & Outro equipamento de transporte \\
\hline 2 & $\begin{array}{l}\text { Mineração e extração de produtos } \\
\text { energéticos* }\end{array}$ & 20 & $\begin{array}{l}\text { Outras manufaturas; reparação e instalação } \\
\text { de máquinas e equipamentos }\end{array}$ \\
\hline 3 & $\begin{array}{l}\text { Mineração e pedreiras de produtos } \\
\text { não energéticos* }\end{array}$ & 21 & $\begin{array}{l}\text { Serviços de eletricidade, gás, abastecimento } \\
\text { de água, esgoto, resíduos e remediação }\end{array}$ \\
\hline 4 & $\begin{array}{l}\text { Atividades de serviço de suporte de } \\
\text { mineração* }\end{array}$ & 22 & Construção \\
\hline 5 & Alimentos, bebidas e tabaco & 23 & $\begin{array}{l}\text { Comércio no atacado e varejo; reparação de } \\
\text { veículos a motor }\end{array}$ \\
\hline 6 & $\begin{array}{l}\text { Têxteis, vestuário, couro e } \\
\text { produtos relacionados }\end{array}$ & 24 & Transporte e Armazenamento \\
\hline 7 & $\begin{array}{l}\text { Madeira e produtos de madeira e } \\
\text { cortiça }\end{array}$ & 25 & Serviços de alojamento e alimentação \\
\hline 8 & Produtos de papel e impressão & 26 & Publicação, audiovisual e radiodifusão \\
\hline 9 & $\begin{array}{l}\text { Coque e produtos petrolíferos } \\
\text { refinados }\end{array}$ & 27 & Telecomunicações \\
\hline 10 & $\begin{array}{l}\text { Produtos Químicos e } \\
\text { Farmacêuticos }\end{array}$ & 28 & TI e outros serviços de informação \\
\hline 11 & Produtos de borracha e plástico & 29 & Atividades financeiras e de seguros \\
\hline 12 & $\begin{array}{l}\text { Outros produtos minerais não } \\
\text { metálicos }\end{array}$ & 30 & Atividades imobiliárias \\
\hline 13 & Metais básicos & 31 & Outros serviços do setor empresarial \\
\hline 14 & Produtos de metal fabricados & 32 & $\begin{array}{l}\text { Admin. pública e defesa; segurança social } \\
\text { obrigatória }\end{array}$ \\
\hline 15 & $\begin{array}{l}\text { Computador, produtos eletrônicos } \\
\text { e ópticos }\end{array}$ & 33 & Educação \\
\hline 16 & Equipamento elétrico & 34 & Saúde humana e trabalho social \\
\hline 17 & Máquinas e equipamentos & 35 & $\begin{array}{l}\text { Artes, entretenimento, recreação e outras } \\
\text { atividades de serviço }\end{array}$ \\
\hline 18 & $\begin{array}{l}\text { Veículos a motor, reboques e } \\
\text { semirreboques }\end{array}$ & 36 & $\begin{array}{l}\text { Domicílios particulares com pessoas } \\
\text { empregadas }\end{array}$ \\
\hline
\end{tabular}

* A matriz do ano de 1995 apresenta os setores de mineração agregados. Fonte: Adaptado de Organisation for Economic Co-operation and Development (2019). 
Quadro 2. Países que possuem matriz de insumo-produto OCDE e não OCDE.

\begin{tabular}{|c|c|c|c|}
\hline \multicolumn{2}{|c|}{ Países da OCDE } & \multicolumn{2}{|c|}{ Economias não OCDE } \\
\hline Alemanha & Irlanda & África do Sul & Malta \\
\hline Austrália & Islândia & Arábia Saudita & Marrocos \\
\hline Áustria & Israel & Argentina & Peru \\
\hline Bélgica & Itália & Brasil & Romênia \\
\hline Canadá & Japão & Brunei & Rússia \\
\hline Chile & Letônia & Bulgária & Singapura \\
\hline Coreia & Luxemburgo & Camboja & Tailândia \\
\hline Dinamarca & México & China & Taiwan \\
\hline Eslováquia & Noruega & Chipre & Tunísia \\
\hline Eslovênia & Nova Zelândia & Colômbia & Vietnã \\
\hline Espanha & Polônia & Costa Rica & \\
\hline Estados Unidos & Portugal & Croácia & \\
\hline Estônia & Reino Unido & Filipinas & \\
\hline Finlândia & República Tcheca & Hong Kong & \\
\hline França & Suíça & Índia & \\
\hline Grécia & Suécia & Indonésia & \\
\hline Holanda & Turquia & Lituânia & \\
\hline Hungria & & Malásia & \\
\hline
\end{tabular}

\subsection{Dimensionamento do complexo agroindustrial (PIB do Agronegócio)}

A estimativa do PIB do agronegócio foi realizada de acordo com a metodologia descrita no trabalho de Furtuoso et al. (1998), no qual é analisada a cadeia produtiva da agropecuária para trás e para frente. A metodologia foi aplicada aos dados obtidos na OCDE (Organisation for Economic Co-operation and Development, 2019) para 63 países e Restante do mundo (agregado em Outros países).

O agronegócio é composto pelos agregados (I) Insumos, (II) Agropecuária, (III) Indústria e (IV) Distribuição. O método de mensuração do Produto Interno Bruto (PIB) do complexo agroindustrial leva em consideração que o primeiro agregado são os insumos para o setor (1) Agropecuária, silvicultura e pesca. Os valores monetários destes insumos adquiridos pelo setor agropecuário são divulgados nas matrizes de insumo-produto. O agregado II é o setor agropecuário, que abrange todas as atividades de produção animal e vegetal, extrativismo e pesca. Os setores do agregado III (indústria) são (5) Alimentos, bebidas e tabaco; (6) Têxteis, vestuário, couro e produtos relacionados; (7) Madeira e produtos de madeira e cortiça; e (8) Produtos de papel e impressão. $O$ agregado IV se refere aos setores relacionados ao comércio e serviços (setores 23 a 36 do Quadro 1).

A mensuração do agregado I inicia-se multiplicando os valores das colunas dos insumos utilizados pelo setor Agropecuária pelos respectivos coeficientes de valor adicionado $\left(C V A_{i}\right)$, onde tem-se $i=34$ setores nas tabelas de 1995 e $i=36$ setores nas tabelas de 2015 . A diferença é devida à desagregação do setor de Mineração, que em 1995 constituía um único setor e foi desagregado em três setores no ano de 2015. O PIB do agregado I é calculado por: 
$P I B_{I}=\sum_{i=1}^{n} z_{i} \times C V A_{i}$

Onde:

$P I B$, é o PIB do agregado I (insumos),

$z_{i}$ é o valor total do insumo do setor $i$ para a agropecuária e

$C V A_{i}$ é o coeficiente de valor adicionado do setor $i$.

Os Coeficientes de Valor Adicionado $\left(C V A_{i}\right)$ são obtidos pela divisão do Valor Adicionado a Preços de Mercado de cada setor ${ }^{1}\left(V A_{P M_{i}}\right)$ pela respectiva produção $\left(X_{i}\right)$ :

$C V A_{i}=\frac{V A_{P M_{i}}}{X_{i}}$

A mensuração do Agregado II considera no cálculo o Valor Adicionado do setor (1) Agropecuária, silvicultura e pesca e subtrai o valor adicionado dos insumos (agregado I). Tem-se então que:

$P I B_{I I}=V A A_{P M}-\sum_{i=1}^{n} z_{i} \times C V A_{i}$

Onde:

$P I B_{\|}$é o PIB do agregado II (Agropecuária) e

$V A A_{P M}$ é o Valor Adicionado da Agropecuária e as outras variáveis são como as definidas anteriormente.

O Agregado (III) é composto pelas agroindústrias identificadas pelos indicadores: a) demanda por produtos agrícolas; b) participação dos produtos agropecuários no total de insumos do setor; e c) as atividades econômicas que efetuam a primeira, segunda e terceira transformações das matérias-primas agrícolas. A mensuração do Agregado (III) é realizada pelo somatório dos valores adicionados pelos setores agroindustriais subtraídos dos valores adicionados destes setores que foram utilizados como insumos do Agregado (II). Os setores do agregado III (indústria) são (5) Alimentos, bebidas e tabaco; (6) Têxteis, vestuário, couro e produtos relacionados; (7) Madeira e produtos de madeira e cortiça; e (8) Produtos de papel e impressão. Temos que:

$P I B_{I I I}=\sum_{i=1}^{k}\left(V A_{P M_{i}}-z_{i} \times C V A_{i}\right)$

Onde:

$P I B_{I I I}$ é o PIB do agregado (III) da indústria,

$k=4$ indústrias de base agrícola.

A estimativa do Agregado (IV) considera o Valor Adicionado dos setores relativos ao Transporte, Comércio e segmentos de Serviços (setores 23 a 36 do Quadro 1). A parcela relativa ao agronegócio do Valor Adicionado total dos setores de comércio e serviços é calculada pela participação dos produtos agropecuários e agroindustriais na demanda final de produtos. 0 processo de cálculo do Valor Adicionado do Agregado IV inicia-se com a definição da Demanda Final Doméstica (DFD):

$D F D=D F G-I I L_{D F}-P I_{D F}$

${ }^{1}$ O Valor Adicionado a preços de mercado é obtido pela soma do valor adicionado a preços básicos aos impostos indiretos líquidos de subsídios sobre produtos, resultando na seguinte expressão: VAPM = VAPB + IIL. Sendo: VAPM = Valor Adicionado a Preços de Mercado; VAPB = Valor Adicionado a Preços Básicos; IIL = Impostos Indiretos Líquidos. 
Onde:

$D F D$ é a demanda final doméstica

$D F G$ é a demanda final global

$I / L_{D F}$ são os impostos indiretos líquidos pagos pela demanda final

$P l_{D F}$ são os produtos importados pela demanda final.

A margem de comercialização dos setores de comércio e serviços (MC) é calculada por:

$M C=V A T_{P M}+V A C_{P M}+V A S_{P M}$

Onde:

MC é a margem de comercialização

$V A T_{P M}$ é o valor adicionado do setor transporte a preços de mercado

$V A C_{P M}$ é o valor adicionado do setor comércio a preços de mercado

$V A S_{P M}$ é o valor adicionado do setor serviços a preços de mercado.

Utiliza-se a margem de comercialização (MC) e a Demanda Final Doméstica (DFD) no cálculo do agregado de Comércio e Serviços (Distribuição de produtos do complexo agroindustrial):

$P I B_{I V}=M C \times \frac{D F_{A}+\sum_{i=l}^{k} D F_{k}}{D F D}$

Onde:

$P I B_{I V}$ é o PIB do agregado IV

$D F D$ é a demanda final doméstica

$D F_{A}$ é a demanda final da agropecuária

$D F_{k}$ é a demanda final dos setores agroindustriais $(k=4)$.

O PIB total do Agronegócio é dado pela soma dos seus agregados, temos que:

$P I B_{A G R O}=P I B_{I}+P I B_{I I}+P I B_{I I I}+P I B_{I V}$

Onde:

$P I B_{A G R O}$ é o PIB do Agronegócio.

Considerando que os resultados estão em valores monetários correntes (dólares americanos), os valores serão utilizados em valores percentuais para tornar possível a análise comparativa entre os países, evolução do agronegócio no mundo, relações da estrutura de valor (composição da renda) do complexo agroindustrial e participação na economia com o Índice de Desenvolvimento Humano (IDH).

\subsection{Coeficiente de correlação de Pearson}

Para mensurar a relação entre a participação do agronegócio na economia e da estrutura do valor adicionado com o Índice de Desenvolvimento Humano (IDH), foi utilizado o coeficiente de Pearson, que mede o grau da correlação e sua direção (positiva ou negativa) entre duas variáveis. De acordo com Hoffmann (2006), o cálculo do coeficiente de correlação de Pearson é dado por:

$\rho=\frac{\sum_{i=I}^{n}\left(x_{i}-\bar{x}\right)\left(y_{i}-\bar{y}\right)}{\sqrt{\sum_{i=I}^{n}\left(x_{i}-\bar{x}\right)^{2}} \cdot \sqrt{\sum_{i=I}^{n}\left(y_{i}-\bar{y}\right)^{2}}}$ 


\section{Resultados e discussão}

A metodologia proposta por Furtuoso et al. (1998) para mensuração do complexo agroindustrial foi aplicada para 63 países com base nas matrizes de insumo-produto da OCDE (Organisation for Economic Co-operation and Development, 2019) para os anos de 1995 e 2015. Os resultados são apresentados e discutidos nesta seção de acordo com a revisão de literatura.

\subsection{Dimensionamento do complexo agroindustrial dos países no ano de 1995}

A Tabela 1 possui os valores do Produto Interno Bruto (PIB) total, PIB do agronegócio e a participação do agronegócio na economia em termos percentuais para o ano de 1995. O cálculo foi realizado para 63 países que participavam com 93\% do PIB mundial, Outros Países (Restante do mundo) e o somatório (mundo). Os valores do Índice de Desenvolvimento Humano (IDH) também estão presentes na Tabela 1. Os países foram classificados em ordem crescente de acordo com o IDH.

Os resultados mostram que o agronegócio participava com $18,4 \%$ do PIB mundial e os maiores valores absolutos no ano de 1995 eram Estados Unidos (936 bilhões US\$), Japão (702 bilhões US\$) e China (308 bilhões US\$), Alemanha (291 bilhões US\$) e França (247 bilhões US\$). Os maiores valores percentuais de participação do agronegócio no PIB do país eram Camboja (75\%), Vietnã (50\%) e Marrocos (48\%). O agregado Outros países (Restante do mundo) apresentou o valor de 33,1\%. Por outro lado, os países que apresentaram menor participação do agronegócio na economia foram Brunei (3\%), Singapura (5\%) e Luxemburgo (8\%). No Brasil, o agronegócio respondia por 24\% do PIB total com 164 bilhões de dólares, o IDH era 0,65.

Países desenvolvidos como Estados Unidos, Alemanha, Japão e Suíça possuíam no máximo 13,8\% de participação do agronegócio em suas economias e Índice de Desenvolvimento Humano maior que 0,83 . Os setores indústria e serviços apresentavam mais de $80 \%$ de participação no PIB do Agronegócio. Os setores industriais e de serviços são fortes e alta exigência da população em qualidade de produtos.

Economias em desenvolvimento como China, Índia, Marrocos, Vietnã e Camboja apresentaram valores acima de $43 \%$ de participação do agronegócio na economia e IDH abaixo de 0,55. A participação dos setores industrial e serviços juntos não ultrapassava 64\% do PIB do agronegócio. Estes países necessitam de alimentos a baixo custo para populações pouco exigentes em qualidade com indústria alimentar e setores de serviços em desenvolvimento.

Os resultados mostram que, apesar de os países possuírem características específicas de clima, solo, tamanho e produtos agropecuários, nações que apresentam maiores valores de Índice de Desenvolvimento Humano possuem menor participação do agronegócio na economia e a composição da renda no agronegócio beneficia os setores industrial e de serviços.

Tabela 1. Produto Interno Bruto (PIB total), Produto Interno Bruto do Agronegócio, participação e Índice de Desenvolvimento Humano (IDH) dos países classificados em ordem crescente do IDH, 1995.

\begin{tabular}{|c|c|c|c|c|c|c|c|c|}
\hline \multirow{2}{*}{ País } & \multirow{2}{*}{$\begin{array}{c}\text { PIB total } \\
\text { (bilhões US\$) }\end{array}$} & \multirow{2}{*}{$\begin{array}{c}\text { PIB do } \\
\text { Agronegócio } \\
\text { (bilhões de US\$) }\end{array}$} & \multicolumn{4}{|c|}{ Agregados (\%) } & \multirow{2}{*}{$\begin{array}{l}\text { Participação } \\
\text { do Agronegócio } \\
\text { (\%) }\end{array}$} & \multirow{2}{*}{$I D H$} \\
\hline & & & I & II & III & $I V$ & & \\
\hline 1. Estados Unidos & 6784,00 & 936,14 & 6,38 & 2,81 & 37,17 & 53,65 & 13,80 & 0,88 \\
\hline 2. Japão & 5290,96 & 702,32 & 5,33 & 7,86 & 42,12 & 44,69 & 13,27 & 0,84 \\
\hline 3. China & 708,12 & 308,48 & 14,67 & 31,98 & 26,85 & 26,49 & 43,56 & 0,55 \\
\hline 4. Alemanha & 2334,59 & 291,16 & 4,85 & 5,65 & 39,01 & 50,49 & 12,47 & 0,83 \\
\hline
\end{tabular}

Fonte: Calculado pelos autores a partir de dados da OCDE (Organisation for Economic Co-operation and Development, 2019) e UNDP (United Nations Development Programme, 2019). 
Tabela 1. Continuação...

\begin{tabular}{|c|c|c|c|c|c|c|c|c|}
\hline \multirow{2}{*}{ País } & \multirow{2}{*}{$\begin{array}{c}\text { PIB total } \\
\text { (bilhões US\$) }\end{array}$} & \multirow{2}{*}{$\begin{array}{c}\text { PIB do } \\
\text { Agronegócio } \\
\text { (bilhões de US\$) }\end{array}$} & \multicolumn{4}{|c|}{ Agregados (\%) } & \multirow{2}{*}{$\begin{array}{l}\text { Participação } \\
\text { do Agronegócio } \\
\text { (\%) }\end{array}$} & \multirow{2}{*}{$I D H$} \\
\hline & & & I & II & III & IV & & \\
\hline 5. França & 1449,96 & 247,03 & 7,73 & 11,48 & 28,81 & 51,98 & 17,04 & 0,83 \\
\hline 6. Itália & 1051,54 & 212,03 & 3,71 & 12,44 & 35,76 & 48,10 & 20,16 & 0,80 \\
\hline 7. Reino unido & 1088,29 & 172,20 & 5,19 & 6,40 & 41,02 & 47,40 & 15,82 & 0,84 \\
\hline 8. Brasil & 671,35 & 164,02 & 6,42 & 16,66 & 29,89 & 47,03 & 24,43 & 0,65 \\
\hline 9. Indonésia & 351,59 & 149,45 & 9,24 & 49,19 & 11,28 & 30,29 & 42,51 & 0,56 \\
\hline 10. Espanha & 558,25 & 120,39 & 5,90 & 18,93 & 27,07 & 48,11 & 21,57 & 0,80 \\
\hline 11. Índia & 225,18 & 104,76 & 3,12 & 29,82 & 35,00 & 32,06 & 46,52 & 0,46 \\
\hline 12. Canadá & 557,86 & 104,12 & 7,23 & 8,71 & 36,95 & 47,11 & 18,66 & 0,86 \\
\hline 13. Coreia & 497,81 & 99,48 & 5,12 & 25,06 & 30,04 & 39,78 & 19,98 & 0,78 \\
\hline 14. México & 318,18 & 76,69 & 6,48 & 15,57 & 33,79 & 44,16 & 24,10 & 0,67 \\
\hline 15. Turquia & 218,68 & 74,21 & 10,79 & 23,89 & 30,55 & 34,77 & 33,93 & 0,61 \\
\hline 16. Holanda & 387,89 & 73,35 & 6,90 & 11,00 & 30,78 & 51,32 & 18,91 & 0,86 \\
\hline 17. Rússia & 287,11 & 63,55 & 17,08 & 17,28 & 24,46 & 41,18 & 22,13 & 0,70 \\
\hline 18. Tailândia & 169,00 & 58,61 & 5,38 & 20,85 & 35,97 & 37,79 & 34,68 & 0,61 \\
\hline 19. Austrália & 360,41 & 57,40 & 7,36 & 16,36 & 35,28 & 41,00 & 15,93 & 0,88 \\
\hline 20. Argentina & 242,39 & 56,25 & 9,30 & 11,41 & 29,63 & 49,66 & 23,21 & 0,73 \\
\hline 21. Suíça & 315,10 & 43,18 & 6,26 & 9,24 & 37,84 & 46,66 & 13,70 & 0,85 \\
\hline 22. Taiwan & 263,40 & 42,98 & 8,54 & 12,85 & 32,41 & 46,21 & 16,32 & 0,85 \\
\hline 23. Suécia & 230,16 & 41,42 & 3,15 & 13,56 & 36,36 & 46,94 & 17,99 & 0,86 \\
\hline 24. Bélgica & 261,59 & 40,13 & 3,94 & 5,89 & 36,21 & 53,96 & 15,34 & 0,85 \\
\hline 25. Áustria & 216,95 & 35,81 & 5,52 & 10,73 & 33,31 & 50,45 & 16,51 & 0,82 \\
\hline 26. Polônia & 126,49 & 35,67 & 14,98 & 13,78 & 29,42 & 41,82 & 28,20 & 0,74 \\
\hline 27. Filipinas & 82,37 & 34,83 & 11,30 & 39,51 & 20,93 & 28,27 & 42,29 & 0,60 \\
\hline 28. Grécia & 120,12 & 34,48 & 8,93 & 20,67 & 22,66 & 47,75 & 28,70 & 0,77 \\
\hline 29. Finlândia & 117,79 & 32,32 & 5,80 & 9,99 & 37,53 & 46,68 & 27,44 & 0,82 \\
\hline 30. Colômbia & 108,38 & 31,16 & 5,84 & 25,84 & 24,56 & 43,76 & 28,75 & 0,63 \\
\hline 31. Dinamarca & 162,05 & 31,08 & 8,40 & 8,08 & 29,42 & 54,10 & 19,18 & 0,83 \\
\hline 32. Portugal & 106,34 & 29,69 & 5,04 & 15,54 & 30,10 & 49,32 & 27,92 & 0,76 \\
\hline 33. África do Sul & 140,78 & 29,43 & 5,85 & 12,02 & 33,88 & 48,25 & 20,90 & 0,65 \\
\hline 34. Malásia & 98,90 & 26,82 & 7,25 & 38,08 & 23,65 & 31,03 & 27,12 & 0,68 \\
\hline 35. Chile & 71,28 & 21,53 & 6,92 & 11,12 & 38,17 & 43,79 & 30,21 & 0,73 \\
\hline 36. Noruega & 133,19 & 20,97 & 5,89 & 13,30 & 29,85 & 50,96 & 15,74 & 0,88 \\
\hline 37. Arábia Saudita & 143,87 & 17,90 & 9,27 & 38,13 & 16,20 & 36,40 & 12,44 & 0,72 \\
\hline 38. Nova Zelândia & 58,01 & 17,80 & 10,69 & 12,20 & 31,41 & 45,70 & 30,68 & 0,85 \\
\hline 39. Irlanda & 61,47 & 17,07 & 5,61 & 20,19 & 31,98 & 42,22 & 27,77 & 0,80 \\
\hline 40. Marrocos & 35,57 & 16,96 & 8,52 & 30,85 & 22,05 & 38,59 & 47,66 & 0,49 \\
\hline 41. Romênia & 36,45 & 15,18 & 17,58 & 27,37 & 27,24 & 27,81 & 41,64 & 0,69 \\
\hline 42. Peru & 47,94 & 14,53 & 4,76 & 24,86 & 27,53 & 42,85 & 30,31 & 0,64 \\
\hline 43. Hong Kong & 137,50 & 13,36 & 0,72 & 0,66 & 35,60 & 63,02 & 9,72 & 0,81 \\
\hline 44. Israel & 91,32 & 12,94 & 5,83 & 10,86 & 34,27 & 49,05 & 14,17 & 0,82 \\
\hline $\begin{array}{l}\text { 45. República } \\
\text { Tcheca }\end{array}$ & 54,61 & 11,47 & 8,93 & 14,86 & 35,36 & 40,86 & 21,01 & 0,75 \\
\hline 46. Hungria & 40,16 & 11,39 & 12,76 & 16,25 & 25,52 & 45,48 & 28,36 & 0,74 \\
\hline 47. Vietnã & 19,92 & 9,92 & 24,71 & 29,89 & 17,41 & 27,99 & 49,78 & 0,53 \\
\hline 48. Tunísia & 18,09 & 7,14 & 3,58 & 27,96 & 28,28 & 40,18 & 39,47 & 0,61 \\
\hline 49. Croácia & 18,82 & 5,77 & 14,10 & 15,37 & 29,96 & 40,57 & 30,64 & 0,70 \\
\hline
\end{tabular}

Fonte: Calculado pelos autores a partir de dados da OCDE (Organisation for Economic Co-operation and Development, 2019) e UNDP (United Nations Development Programme, 2019). 
Tabela 1. Continuação...

\begin{tabular}{|c|c|c|c|c|c|c|c|c|}
\hline \multirow{2}{*}{ País } & \multirow{2}{*}{$\begin{array}{c}\text { PIB total } \\
\text { (bilhões US\$) }\end{array}$} & \multirow{2}{*}{$\begin{array}{c}\text { PIB do } \\
\text { Agronegócio } \\
\text { (bilhões de US\$) }\end{array}$} & \multicolumn{4}{|c|}{ Agregados (\%) } & \multirow{2}{*}{$\begin{array}{l}\text { Participação } \\
\text { do Agronegócio } \\
\text { (\%) }\end{array}$} & \multirow{2}{*}{ IDH } \\
\hline & & & I & II & III & IV & & \\
\hline 50. Bulgária & 12,58 & 5,35 & 21,67 & 19,84 & 21,22 & 37,28 & 42,51 & 0,70 \\
\hline 51. Costa Rica & 11,04 & 4,71 & 7,13 & 24,02 & 27,35 & 41,49 & 42,64 & 0,69 \\
\hline 52. Eslovênia & 19,35 & 4,56 & 7,40 & 11,51 & 39,07 & 42,03 & 23,58 & 0,78 \\
\hline 53. Eslováquia & 18,24 & 4,33 & 12,75 & 12,72 & 36,14 & 38,39 & 23,74 & 0,75 \\
\hline 54. Singapura & 83,50 & 3,94 & 1,12 & 2,19 & 58,03 & 38,66 & 4,72 & 0,77 \\
\hline 55. Lituânia & 6,30 & 2,45 & 15,78 & 9,14 & 30,92 & 44,16 & 38,80 & 0,70 \\
\hline 56. Camboja & 3,24 & 2,44 & 3,59 & 63,60 & 9,87 & 22,94 & 75,29 & 0,39 \\
\hline 57. Islândia & 6,00 & 2,13 & 8,16 & 23,95 & 26,90 & 40,98 & 35,56 & 0,83 \\
\hline 58. Chipre & 8,64 & 2,11 & 5,96 & 14,76 & 28,58 & 50,70 & 24,45 & 0,79 \\
\hline 59. Letônia & 5,00 & 1,88 & 12,45 & 11,33 & 35,02 & 41,20 & 37,55 & 0,67 \\
\hline 60. Luxemburgo & 19,52 & 1,64 & 2,21 & 10,92 & 40,59 & 46,28 & 8,39 & 0,81 \\
\hline 61. Estônia & 3,41 & 1,11 & 9,60 & 8,84 & 34,75 & 46,81 & 32,66 & 0,73 \\
\hline 62. Malta & 3,17 & 0,60 & 4,94 & 10,16 & 39,22 & 45,69 & 18,98 & 0,76 \\
\hline 63. Brunei & 4,86 & 0,12 & 44,56 & 1,53 & 14,64 & 39,27 & 2,52 & 0,81 \\
\hline Outros países & 1149,04 & 380,37 & 6,34 & 43,71 & 19,35 & 30,61 & 33,10 & - \\
\hline Mundo & 28225,66 & 5192,30 & 6,99 & 15,82 & 32,84 & 44,35 & 18,40 & - \\
\hline
\end{tabular}

Fonte: Calculado pelos autores a partir de dados da OCDE (Organisation for Economic Co-operation and Development, 2019) e UNDP (United Nations Development Programme, 2019).

\subsection{Dimensionamento do complexo agroindustrial dos países no ano de 2015}

Os resultados do dimensionamento do agronegócio dos países em análise para o ano de 2015 estão na Tabela 2. Comparando os resultados obtidos nas Tabelas 1 e 2, nota-se a diminuição de $18,4 \%$ para 15,2\% a participação do agronegócio na economia mundial. O grupo de países analisado continuou representando a maior parte do PIB mundial com 92\% e os maiores valores absolutos do PIB do agronegócio correspondem a China (2496 Bilhões US\$), Estados Unidos (1395 Bilhões US\$), Índia (637 Bilhões US\$), Japão (414 Bilhões US\$) e Brasil (316 Bilhões US\$). Vale destacar a evolução dos Outros Países, cujo agronegócio passou a produzir 1558 bilhões de dólares com $27,7 \%$ de participação na economia do restante do mundo. Em termos percentuais, os maiores valores da participação do agronegócio eram Camboja (63\%), Vietnã (42\%) e Filipinas (40\%). Os países com menor participação do agronegócio na formação do PIB eram Luxemburgo (3\%), Singapura (3\%) e Brunei (4\%).

Em 2015, o Brasil apresentou PIB do agronegócio de 316 bilhões de dólares em valor corrente, isto representava participação de 19,1\% do PIB total do país. Este resultado se aproxima do obtido pelo Centro de Estudos Avançados em Economia Aplicada (CEPEA) que calculou a participação do agronegócio do Brasil em 2015 de 20,5\%. Neste período, o Brasil continua acima da média mundial de 15,2\%. Em relação à composição da renda no complexo agroindustrial no período 1995-2015, os países mais pobres (Camboja, Índia e Marrocos) aumentaram a participação dos insumos no PIB do agronegócio. Isto indica um esforço no aumento da produtividade do setor agropecuário, o qual tem o principal papel de fornecedor de alimentos baratos para a população. Porém, os setores industrial e serviços (agregados III e IV) são pouco desenvolvidos e apresentam baixa participação na composição da renda do agronegócio.

Países com mais de $25 \%$ de participação do PIB do agronegócio na economia possuíam IDH entre 0,57 (Camboja) e máximo de 0,82 (Argentina). Estas economias em desenvolvimento 
apresentaram os agregados III e IV participando juntos com no máximo 70\% da renda do complexo agroindustrial. Os países em desenvolvimento aumentaram a participação dos agregados da indústria e serviços. Isto ocorreu por motivo do aumento do processamento dos produtos básicos (matéria-prima) e adição de serviços para atender a exigências crescentes da demanda em relação à qualidade e diferenciação dos produtos. Pode-se observar esta tendência para Brasil, México, Turquia e China. O agronegócio nestes países em desenvolvimento cumpre diferentes papéis, descritos por Leones et al. (1994), de fornecimento de alimento e fibras a baixos preços para uma demanda pouco exigente nos países mais pobres e, com o desenvolvimento, o aumento da exigência por qualidade e conveniência da demanda leva ao aumento da agroindustrialização e adição de serviços.

Nações com IDH acima de 0,9 apresentaram percentuais de no máximo 10\% de participação do agronegócio na economia. Estes países possuem os setores industrial e serviços (agregados III e IV) bem desenvolvidos com participação mínima de $70 \%$ na composição da renda do agronegócio. Os países com alto IDH mostraram aumento da participação do setor de serviços e diminuição do percentual da indústria na composição da estrutura da renda do agronegócio. Exemplos de países com estas caraterísticas são Suécia, Estados Unidos, Holanda, Noruega e Austrália. Os resultados do estudo estão de acordo com as afirmações de Leones et al. (1994) e Pingali (2007) de que, em países desenvolvidos, os setores de processamento e distribuição são fortes, pois os consumidores exigem qualidade, conveniência e facilidades no uso dos produtos. O governo apoia o interesse dos produtores rurais e subsidia as atividades.

Tabela 2. Produto Interno Bruto (PIB total), Produto Interno Bruto do Agronegócio, participação e Índice de Desenvolvimento Humano (IDH) dos países classificados em ordem crescente do IDH, 2015.

\begin{tabular}{|c|c|c|c|c|c|c|c|c|}
\hline \multirow{2}{*}{ País } & \multirow{2}{*}{$\begin{array}{c}\text { PIB total } \\
\text { (bilhões US\$) }\end{array}$} & \multirow{2}{*}{$\begin{array}{c}\text { PIB do } \\
\text { Agronegócio } \\
\text { (bilhões de US\$) }\end{array}$} & \multicolumn{4}{|c|}{ Agregados (\%) } & \multirow{2}{*}{$\begin{array}{l}\text { Participaçấo do } \\
\text { Agronegócio (\%) }\end{array}$} & \multirow{2}{*}{$I D H$} \\
\hline & & & I & II & III & $I V$ & & \\
\hline 1. China & 10474,20 & 2496,12 & 14,98 & 20,78 & 31,93 & 32,32 & 23,83 & 0,74 \\
\hline $\begin{array}{l}\text { 2. Estados } \\
\text { Unidos }\end{array}$ & 17662,37 & 1395,10 & 8,41 & 5,60 & 28,93 & 57,07 & 7,90 & 0,92 \\
\hline 3. Índia & 1997,55 & 637,35 & 10,92 & 42,62 & 14,72 & 31,74 & 31,91 & 0,63 \\
\hline 4. Japão & 4351,65 & 413,50 & 5,83 & 5,93 & 38,87 & 49,37 & 9,50 & 0,91 \\
\hline 5. Brasil & 1652,32 & 316,01 & 7,13 & 19,53 & 23,51 & 49,83 & 19,13 & 0,76 \\
\hline 6. Indonésia & 843,00 & 287,10 & 9,04 & 31,27 & 27,57 & 32,12 & 34,06 & 0,69 \\
\hline 7. Alemanha & 3193,07 & 244,98 & 4,99 & 3,39 & 40,08 & 51,53 & 7,67 & 0,93 \\
\hline 8. Itália & 1727,83 & 244,52 & 3,89 & 11,70 & 33,25 & 51,15 & 14,15 & 0,88 \\
\hline 9. França & 2288,20 & 234,80 & 8,25 & 9,29 & 28,76 & 53,70 & 10,26 & 0,90 \\
\hline 10. Peru & 795,54 & 200,31 & 9,60 & 20,79 & 29,04 & 40,57 & 25,18 & 0,75 \\
\hline 11. Reino Unido & 2721,28 & 199,34 & 4,43 & 5,56 & 37,29 & 52,72 & 7,33 & 0,92 \\
\hline 12. México & 1124,17 & 194,90 & 6,10 & 13,29 & 34,39 & 46,22 & 17,34 & 0,77 \\
\hline 13. Argentina & 580,84 & 185,49 & 9,28 & 21,11 & 30,82 & 38,79 & 31,93 & 0,82 \\
\hline 14. Espanha & 1131,56 & 174,96 & 5,07 & 12,73 & 28,11 & 54,09 & 15,46 & 0,89 \\
\hline 15. Rússia & 1299,83 & 166,70 & 13,43 & 20,17 & 21,89 & 44,51 & 12,83 & 0,81 \\
\hline 16. Canadá & 1493,86 & 163,62 & 9,98 & 6,83 & 30,91 & 52,28 & 10,95 & 0,92 \\
\hline 17. Coreia & 1325,49 & 139,29 & 5,01 & 16,13 & 35,10 & 43,76 & 10,51 & 0,90 \\
\hline 18. Tailândia & 387,57 & 120,31 & 9,62 & 24,02 & 31,34 & 35,01 & 31,04 & 0,74 \\
\hline 19. Austrália & 1190,92 & 116,82 & 13,88 & 12,70 & 25,45 & 47,97 & 9,81 & 0,94 \\
\hline 20. Filipinas & 287,63 & 115,33 & 10,44 & 24,42 & 28,78 & 36,36 & 40,10 & 0,69 \\
\hline 21. Holanda & 720,85 & 81,22 & 7,54 & 8,83 & 27,33 & 56,29 & 11,27 & 0,93 \\
\hline
\end{tabular}

Fonte: Calculado pelos autores a partir de dados da OCDE (Organisation for Economic Co-operation and Development, 2019) e UNDP (United Nations Development Programme, 2019). 
Tabela 2. Continued...

\begin{tabular}{|c|c|c|c|c|c|c|c|c|}
\hline \multirow{2}{*}{ País } & \multirow{2}{*}{$\begin{array}{c}\text { PIB total } \\
\text { (bilhões US\$) }\end{array}$} & \multirow{2}{*}{$\begin{array}{c}\text { PIB do } \\
\text { Agronegócio } \\
\text { (bilhões de US\$) }\end{array}$} & \multicolumn{4}{|c|}{ Agregados (\%) } & \multirow{2}{*}{$\begin{array}{l}\text { Participação do } \\
\text { Agronegócio (\%) }\end{array}$} & \multirow{2}{*}{$I D H$} \\
\hline & & & I & II & III & IV & & \\
\hline 22. Vietnã & 186,59 & 78,50 & 13,75 & 20,96 & 35,64 & 29,64 & 42,07 & 0,68 \\
\hline 23. Polônia & 444,45 & 71,03 & 9,31 & 6,48 & 36,69 & 47,51 & 15,98 & 0,86 \\
\hline 24. Malásia & 294,90 & 64,64 & 10,78 & 31,08 & 23,10 & 35,05 & 21,92 & 0,80 \\
\hline 25. Colômbia & 276,20 & 58,81 & 6,31 & 24,03 & 27,50 & 42,16 & 21,29 & 0,74 \\
\hline $\begin{array}{l}\text { 26. Arábia } \\
\text { Saudita }\end{array}$ & 645,45 & 54,14 & 2,19 & 28,21 & 32,99 & 36,62 & 8,39 & 0,85 \\
\hline 27. Suíça & 669,43 & 47,90 & 4,40 & 5,09 & 40,40 & 50,11 & 7,15 & 0,94 \\
\hline 28. Hong Kong & 303,74 & 46,06 & 1,40 & 1,55 & 37,93 & 59,12 & 15,17 & 0,93 \\
\hline 29. Chile & 231,26 & 45,28 & 9,69 & 12,92 & 31,10 & 46,29 & 19,58 & 0,84 \\
\hline 30. Suécia & 469,98 & 44,54 & 4,72 & 10,04 & 33,98 & 51,27 & 9,48 & 0,93 \\
\hline 31. África do Sul & 297,92 & 43,86 & 7,31 & 9,46 & 34,61 & 48,62 & 14,72 & 0,69 \\
\hline 32. Taiwan & 515,43 & 43,67 & 5,98 & 14,75 & 34,75 & 44,52 & 8,47 & 0,89 \\
\hline 33. Bélgica & 433,34 & 43,16 & 4,24 & 4,11 & 34,73 & 56,92 & 9,96 & 0,91 \\
\hline 34. Irlanda & 279,08 & 42,30 & 3,41 & 3,37 & 55,63 & 37,59 & 15,16 & 0,93 \\
\hline 35. Peru & 181,21 & 41,19 & 5,09 & 24,55 & 29,66 & 40,70 & 22,73 & 0,75 \\
\hline $\begin{array}{l}\text { 36. Nova } \\
\text { Zelândia }\end{array}$ & 170,67 & 38,96 & 12,39 & 9,71 & 27,33 & 50,58 & 22,83 & 0,91 \\
\hline 37. Áustria & 357,64 & 38,52 & 4,90 & 6,93 & 38,31 & 49,85 & 10,77 & 0,90 \\
\hline 38. Romênia & 166,96 & 35,43 & 8,57 & 13,59 & 38,65 & 39,19 & 21,22 & 0,81 \\
\hline 39. Portugal & 183,46 & 34,59 & 4,77 & 7,89 & 35,54 & 51,81 & 18,85 & 0,84 \\
\hline 40. Marrocos & 95,36 & 33,84 & 10,85 & 30,47 & 22,79 & 35,89 & 35,48 & 0,66 \\
\hline 41. Finlândia & 217,73 & 31,30 & 5,84 & 12,09 & 32,32 & 49,76 & 14,37 & 0,92 \\
\hline 42. Grécia & 180,33 & 30,30 & 7,92 & 17,63 & 23,92 & 50,52 & 16,80 & 0,87 \\
\hline 43. Noruega & 361,22 & 29,83 & 9,65 & 11,49 & 26,41 & 52,44 & 8,26 & 0,95 \\
\hline 44. Israel & 289,41 & 27,75 & 7,22 & 9,11 & 29,88 & 53,79 & 9,59 & 0,90 \\
\hline 45. Dinamarca & 281,83 & 24,83 & 9,21 & 8,65 & 24,93 & 57,20 & 8,81 & 0,93 \\
\hline 46. Rep. Tcheca & 178,27 & 20,41 & 8,76 & 13,70 & 36,43 & 41,11 & 11,45 & 0,88 \\
\hline 47. Hungria & 114,11 & 16,14 & 10,52 & 19,95 & 25,96 & 43,57 & 14,15 & 0,83 \\
\hline 48. Tunísia & 41,01 & 12,65 & 7,81 & 22,84 & 30,03 & 39,33 & 30,84 & 0,73 \\
\hline 49. Costa Rica & 51,57 & 12,38 & 7,71 & 15,15 & 26,60 & 50,54 & 24,00 & 0,79 \\
\hline 50. Camboja & 17,52 & 11,07 & 9,06 & 37,24 & 26,17 & 28,18 & 63,19 & 0,57 \\
\hline 51. Eslováquia & 84,50 & 10,06 & 10,46 & 19,74 & 33,73 & 36,07 & 11,90 & 0,85 \\
\hline 52. Bulgária & 46,13 & 8,93 & 9,54 & 15,23 & 31,94 & 43,30 & 19,36 & 0,81 \\
\hline 53. Croácia & 44,49 & 8,74 & 6,31 & 12,33 & 35,37 & 45,99 & 19,64 & 0,83 \\
\hline 54. Lituânia & 38,88 & 8,67 & 8,72 & 9,02 & 36,64 & 45,62 & 22,30 & 0,85 \\
\hline 55. Singapura & 285,97 & 8,54 & 0,26 & 1,18 & 55,32 & 43,24 & 2,99 & 0,93 \\
\hline 56. Letônia & 25,16 & 5,32 & 11,21 & 9,04 & 30,63 & 49,13 & 21,17 & 0,84 \\
\hline 57. Eslovênia & 39,98 & 4,67 & 6,82 & 13,07 & 35,68 & 44,44 & 11,69 & 0,89 \\
\hline 58. Estônia & 21,06 & 4,18 & 6,72 & 10,82 & 34,57 & 47,88 & 19,87 & 0,87 \\
\hline 59. Islândia & 16,12 & 3,55 & 7,58 & 20,67 & 25,70 & 46,05 & 22,03 & 0,93 \\
\hline 60. Chipre & 18,53 & 1,92 & 6,73 & 17,68 & 22,84 & 52,75 & 10,34 & 0,86 \\
\hline 61. Luxemburgo & 54,65 & 1,59 & 3,17 & 7,37 & 49,28 & 40,17 & 2,90 & 0,90 \\
\hline 62. Malta & 9,83 & 0,71 & 3,71 & 14,72 & 36,39 & 45,18 & 7,19 & 0,87 \\
\hline 63. Brunei & 13,10 & 0,48 & 4,54 & 2,45 & 62,11 & 30,91 & 3,68 & 0,85 \\
\hline Outros Países & 5624,05 & 1557,67 & 17,33 & 31,17 & 20,49 & 31,02 & 27,70 & - \\
\hline Mundo & 71508,25 & 10875,78 & 10,94 & 18,83 & 28,82 & 41,42 & 15,21 & - \\
\hline
\end{tabular}

Fonte: Calculado pelos autores a partir de dados da OCDE (Organisation for Economic Co-operation and Development, 2019) e UNDP (United Nations Development Programme, 2019). 
Yan et al. (2011) e Sesso Filho et al. (2019b) apresentaram resultados próximos aos obtidos no presente estudo, mas é importante lembrar que os anos de análise são diferentes. Sesso Filho et al. (2019b) mensuraram em 15\% a participação do agronegócio no mundo no ano de 2009 e os maiores valores absolutos dos países foram da China com 1,3 trilhão de dólares e Estados Unidos com 1,14 trilhão de dólares.

As Figuras 1 e 2 mostram a evolução no período 1995-2015 da participação do agronegócio na economia (\%) e IDH, respectivamente. O aumento do IDH foi acompanhado da diminuição da participação do agronegócio na renda total para 59 dos 63 países do estudo. As exceções são a Argentina, que aumentou de 23,21\% em 1995 para 31,93\% em 2015, Hong Kong e Brunei também apresentaram aumento do valor percentual do PIB do agronegócio na economia. Os países apresentaram aumento do IDH no período de análise com exceção do Camboja. Portanto, pode-se afirmar que a trajetória de desenvolvimento dos países é acompanhada pela diminuição da importância do agronegócio.

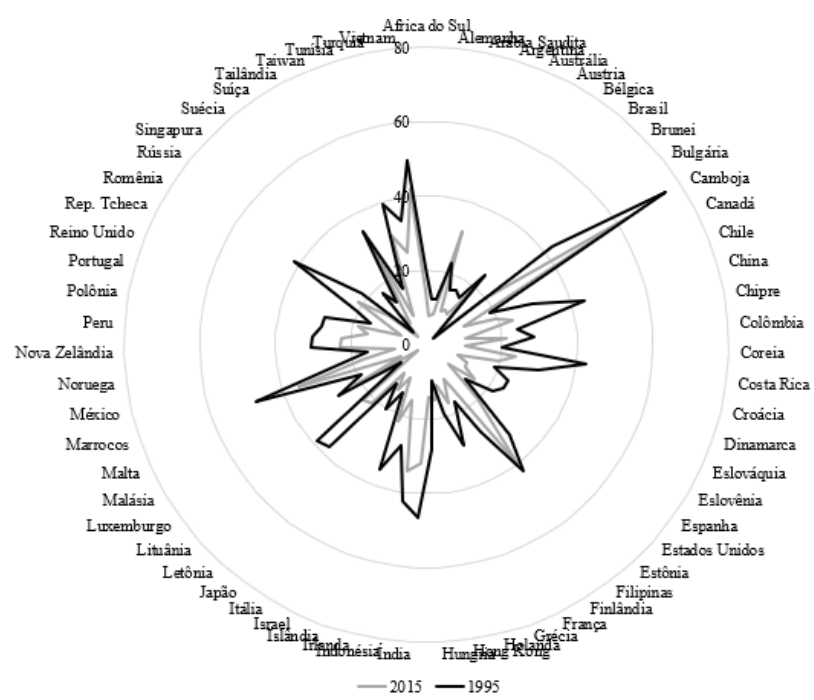

Figura 1. Participação do agronegócio dos países nos anos de 1995 e 2015 em valores percentuais.

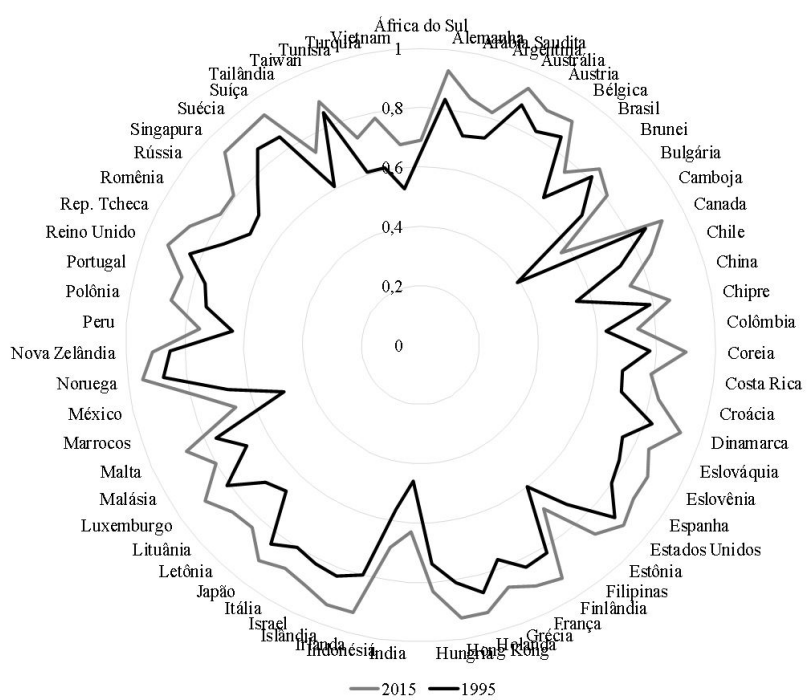

Figura 2. Índice de Desenvolvimento Humano dos países nos anos de 1995 e 2015. 
A Figura 3 ilustra a relação da participação do agronegócio na economia e o Índice de Desenvolvimento Humano (IDH) nos anos de 1995 e 2015. No período de análise 1995-2015, a maior parte dos países mostrou aumento do Índice de Desenvolvimento Humano e diminuição do agronegócio na economia em termos percentuais do Produto Interno Bruto. Nota-se maior dispersão dos dados em 1995 que em 2015, mas em ambos os períodos a relação inversa entre as variáveis está presente.
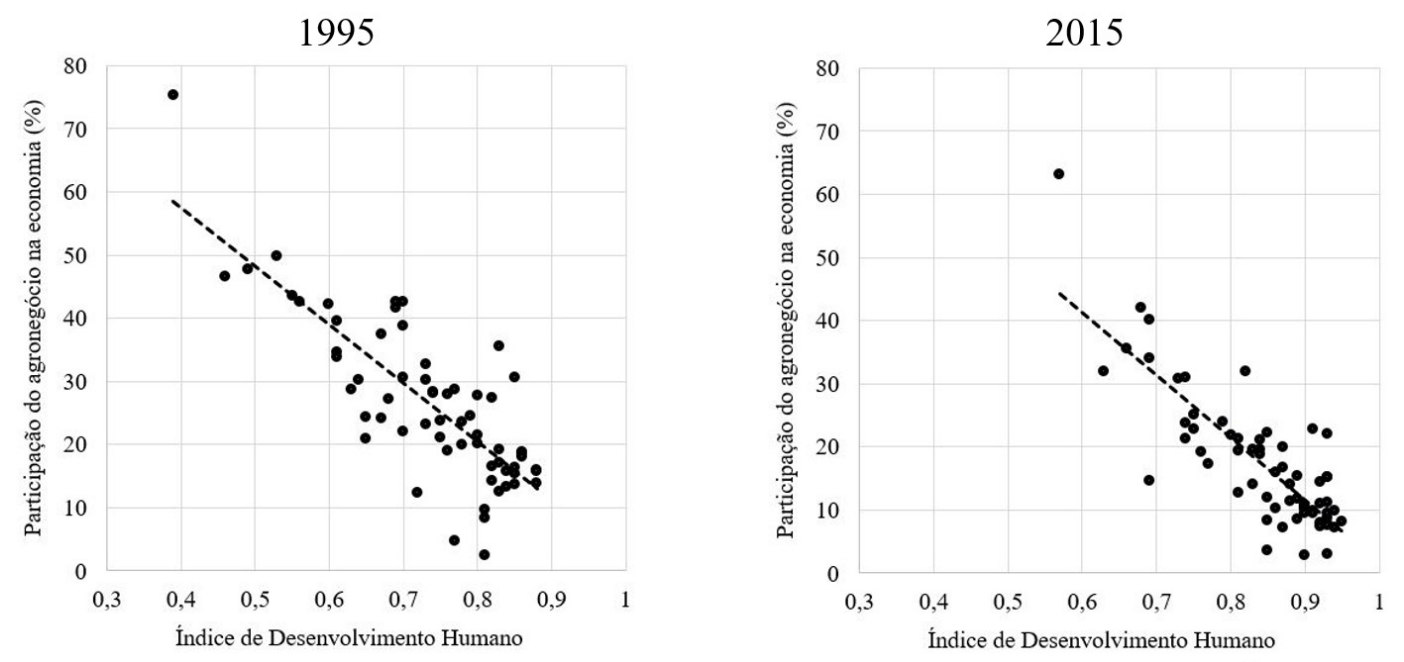

Figura 3. Participação do agronegócio na economia (PIB) dos países do estudo e Índice de Desenvolvimento Humano (IDH). Fonte: resultados da pesquisa.

Para mensurar as relações entre a participação do Produto Interno Bruto do Agronegócio e seus agregados no PIB total e o IDH, foi calculado o coeficiente de correlação de Pearson. A Tabela 3 possui os resultados do coeficiente de correlação de Pearson entre as variáveis participação do agronegócio (PIB Agro) na economia e proporção dos agregados (I) Insumos, (II) Agropecuária, (III) Indústria e (IV) Serviços em valores percentuais e o Índice de Desenvolvimento Humano (IDH). Os valores obtidos para os anos 1995 e 2015 mostram que países com maior IDH apresentam menor participação do PIB do agronegócio ( PIB $_{\text {AGRO }}$ ) no PIB total. Além disso, países com IDH mais alto apresentam menores participações dos Insumos (agregado I) e o setor Agropecuário (agregado II) no PIB do agronegócio em termos percentuais, por outro lado, a Indústria (agregado III) e Serviços (agregado IV) possuem maiores percentuais de participação em países com maiores valores de IDH.

Os resultados do coeficiente de correlação de Pearson entre variações do IDH e variações da participação do agronegócio na economia em termos percentuais e da composição do PIB (agregados) estão na Tabela 3. Os valores obtidos mostram a diminuição da participação do $\mathrm{PIB}_{\mathrm{AGRO}}$ no total da economia, redução das participações dos agregados I e II na estrutura do PIB do agronegócio e crescimento das participações dos agregados III e IV na trajetória de desenvolvimento dos países em análise.

As informações obtidas nos estudos de Reardon \& Barrett (2000) e Byerlee et al. (2009) são de que o desenvolvimento econômico leva os países a diminuírem a participação do agronegócio na economia e aumentarem a participação da indústria e serviços no Produto Interno Bruto do agronegócio. Os cálculos da mensuração do complexo agroindustrial dos países dividido nos agregados propostos por Davis \& Goldberg (1957) pela metodologia de Furtuoso et al. (1998), assim como o cálculo de sua participação na economia e relacionamento com indicadores de 
desenvolvimento, mostraram que os resultados do estudo estão de acordo com as afirmações dos autores. A explicação para estas transformações é de que o papel do agronegócio se modifica com o desenvolvimento e necessidade de atender a uma demanda mais exigente com estímulo à agroindustrialização, diferenciação de produtos e agregação de serviços de acordo com Leones et al. (1994) e Pingali (2007).

Tabela 3. Coeficiente de correlação de Pearson entre o Índice de Desenvolvimento Humano (IDH) e participação do agronegócio (PIB Agro) na economia e proporção dos agregados (I) Insumos, (II) Agropecuária, (III) Indústria e (IV) Serviços em valores percentuais.

\begin{tabular}{|c|c|c|c|}
\hline Período & Variável (\%) & Variável (índice) & $\begin{array}{c}\text { Coeficiente de } \\
\text { correlaçấo }\end{array}$ \\
\hline \multirow[t]{5}{*}{1995} & (I) Insumos & IDH & $-0,13$ \\
\hline & (II) Agropecuária & & $-0,75 * * *$ \\
\hline & (III) Indústria & & $0,50 * \star *$ \\
\hline & (IV) Serviços & & $0,73 * * *$ \\
\hline & $\mathrm{PIB}_{\mathrm{AGRO}}$ & & $-0,81 * \star *$ \\
\hline \multirow[t]{5}{*}{2015} & (I) Insumos & $\mathrm{IDH}$ & $-0,41 * \star \star$ \\
\hline & (II) Agropecuária & & $-0,78 * * *$ \\
\hline & (III) Indústria & & $0,35 * * *$ \\
\hline & (IV) Serviços & & $0,69 * * *$ \\
\hline & PIB $_{\text {AGRO }}$ & & $-0,82 * * *$ \\
\hline \multirow[t]{5}{*}{1995 - 2015} & $\Delta(\mathrm{l})$ Insumos & $\Delta \mathrm{IDH}$ & 0,02 \\
\hline & $\Delta$ (II) Agropecuária & & $-0,52 * \star \star$ \\
\hline & $\Delta$ (III) Indústria & & $0,18 *$ \\
\hline & $\Delta$ (IV) Serviços & & $0,41 * * *$ \\
\hline & $\Delta \mathrm{PIB}_{\mathrm{AGRO}}$ & & $-0,73 * * *$ \\
\hline
\end{tabular}

Significância: * 10\% $(>0,17)$, ** 5\% (>0,21), *** 1\% (>0,3). Fonte: elaborado pelos autores.

\section{Conclusões}

A metodologia de mensuração do complexo agroindustrial com a utilização dos dados de matrizes de insumo-produto se mostrou adequada para ser aplicada para diferentes países. Os resultados obtidos podem ser comparados no tempo e entre os países usando os resultados em termos percentuais considerando a diversidade da estrutura produtiva e tamanho da economia. Além disso, os valores podem ser analisados em conjunto com outros indicadores econômicos e sociais.

Os resultados mostraram que a participação do agronegócio no PIB mundial diminuiu de $18,4 \%$ para 15,2\% e a maior parte dos países (59 em 63) apresentou a mesma tendência no período de 1995 a 2015 simultaneamente com aumento do Índice de Desenvolvimento Humano (IDH). Os maiores valores absolutos do PIB do agronegócio em 2015 correspondem a China (2496 Bilhões US\$), Estados Unidos (1395 Bilhões US\$), Índia (637 Bilhões US\$), Japão (414 Bilhões US\$) e Brasil (316 Bilhões US\$). O Brasil passou da oitava para a quinta posição do PIB do agronegócio no período e a participação na economia diminuiu de $24,4 \%$ para $19 \%$. Os países com maior participação do agronegócio na economia em 2015 foram Camboja (63\%), Vietnã (42\%), Filipinas (40\%), Marrocos (35\%), Indonésia (34\%) e Argentina (32\%).

O desenvolvimento dos países mensurado pelo aumento do IDH foi acompanhado pela diminuição da participação do agronegócio na economia. Além disso, o desenvolvimento é acompanhado pela modificação da estrutura de valor adicionado com a queda da participação do 
setor Agropecuário (agregado II) no PIB do agronegócio em termos percentuais e a participação dos agregados Indústria (agregado III) e Serviços (agregado IV) apresentam aumento dos valores percentuais de participação no agronegócio.

Novos estudos podem ser desenvolvidos para diferentes períodos e maior número de países incorporando variáveis como emprego e emissões atmosféricas no agronegócio. Considerando a padronização das Contas Nacionais e disponibilidade de bases de dados, a metodologia de mensuração de cadeias produtivas pode ser aplicada a diferentes setores da economia em diferentes países, tais como construção e indústria automobilística.

\section{Referências}

Araújo Neto, D. L., \& Costa, E. F. (2005). Dimensionamento do PIB do agronegócio em Pernambuco. Revista de Economia e Sociologia Rural, 43(4), 725-757. http://dx.doi.org/10.1590/S010320032005000400006.

Brigatte, H., \& Teixeira, E. C. (2010). Determinantes do produto e da produtividade total dos fatores da agropecuária brasileira. Revista de Política Agrícola, 2, 5-13. Recuperado em 14 de outubro de 2020, de https://seer.sede.embrapa.br/index.php/RPA/article/view/320/264.

Byerlee, D., de Janvry, A., \& Sadoulet, E. (2009). Agriculture for development: toward a new paradigm. Annual Review of Resource Economics, 1(1), 15-31. https://doi.org/10.1146/ annurev.resource.050708.144239.

Centro de Estudos Avançados em Economia Aplicada - CEPEA. (2019). Recuperado em 12 de dezembro de 2019, de https://www.cepea.esalq.usp.br/br

Cruz, A. C., Teixeira, E. C., \& Gomes, M.F.M. (2009). O PIB do agronegócio no estado de Minas Gerais: uma análise insumo-produto. Revista de Economia e Sociologia Rural, 47(4), 805830. http://dx.doi.org/10.1590/S0103-20032009000400001.

Davis, J. H., \& Goldberg, R. A. (1957). A concept of agribusiness. Journal of Farm Economics, 39(4), 1042-1045.

De Janvry, A. (2010). Agriculture for development: new paradigm and options for success. Agricultural Economics, 41(s1), 17-36. https://doi.org/10.1111/j.1574-0862.2010.00485.x.

Delgado, C. L., Hopkins, J., Kelly, V. A., Hazell, P., Mckenna, A. A., Gruhn, P., Hojjati, B., Sil, H., \& Courbois, C. (1998). Agricultural Growth Linkages in Sub-Saharan Africa. Washington: International Food Policy Research Institute.

Finamore, E. B., \& Montoya, M. A. (2003). PIB, tributos, emprego, salários e saldo comercial no agronegócio gaúcho. Ensaios FEE, 24(1), 93-126. Recuperado em 22 de fevereiro de 2018, de https://revistas.fee.tche.br/index.php/ensaios/article/download/567/807

Fuglie, K. O., Wang, S. L., \& Ball, V. E. (2012). Productivity Growth in Agriculture--An International Perspective. Boston: CABI. https://doi.org/10.1079/9781845939212.0000.

Furtuoso, M. C. O., Barros, G. S. C., \& Guilhoto, J. J. M. (1998). O Produto interno bruto do complexo agroindustrial brasileiro. Revista de Economia e Sociologia Rural, 36, 9-31.

Gilio, L., Silva, A. F., Barros, G. S. de C., Fachinello, A. L., \& Castro, N. R. (2016). O agronegócio em Minas Gerais: evolução do Produto Interno Bruto entre 2004 e 2015. Revista de Economia e Agronegócio, 14(1-3), 41-76. https://doi.org/10.25070/rea.v14i1,2,3.292.

Guilhoto, J.J. M., Assumpção, M., Modolo, D., \& Imori, D. (2007). O PIB do Agronegócio no Brasil e no Estado da Bahia. In: Anais do XLV Congresso da Sociedade Brasileira de Economia, Administração e Sociologia Rural. Brasília: SOBER. 
Guilhoto, J. J. M., Azzoni, C. R., Silveira, F. G., Ichihara, S. M., Diniz, B. P. C., \& Moreira, G. R. C. (2011). PIB da Agricultura Familiar: Brasil - Estados. Brasília: MDA. http://dx.doi.org/10.2139/ ssrn.1803225.

Hayami, Y. K., \& Ruttan, V. W. (1985). Agricultural development: an international perspective. Baltimore: Johns Hopkins University Press.

Hoffmann, R. (2006). Estatística para economistas. São Paulo: Cengage Learning.

Leones, J., Schluter, G., \& Goldman, G. (1994). Redefining agriculture in interindustry analysis. American Journal of Agricultural Economics, 76(5), 1123-1129.

Lewis, W.A. (1954). Economic development with unlimited supplies of labour. The Manchester School, 22, 139-191. https://doi.org/10.1111/j.1467-9957.1954.tb00021.x.

Luz, A. (2014). O mito da produção agrícola de baixo valor agregado. Revista de Política Agrícola, XXIII, 20-39.

Nunes, P. A., \& Parré, J. L. (2013). Dimensionamento do agronegócio paranaense: 2007. Faz Ciência (UNIOESTE), 15, 126-142. Recuperado em 11 de fevereiro de 2018, de http://erevista.unioeste.br/index.php/fazciencia/article/download/7797/5771

Organisation for Economic Co-operation and Development - OECD. (2019). Recuperado em 13 de janeiro de 2019, de http://www.OCDE.org/sti/ind/inter-country-input-output-tables.htm

Pingali, P. (2007). Agricultural growth and economic development: a view through the globalization lens. Agricultural Economics, 37, 1-12.

Reardon, T., \& Barrett, C. (2000). Agroindustrialization, globalization, and international development: an overview of issues, patterns, and determinants. Agricultural Economics, 23, 195-205.

Schluter, G., Lee, C., \& Edmondson, W. (1986). Income and employment generation in the food and fiber system. Agribusiness, 2(2), 143-158. https://doi.org/10.1002/15206297(198622)2:2<143::AID-AGR2720020202>3.0.CO;2-H.

Schultz, T. W. (1964). Transforming traditional agriculture(212 p). New Haven CT: Yale University Press.

Sesso Filho, U. A., Borges, L. T., Pompermayer, P., Zapparoli, I. D., \& Brene, P. R. A. (2019a). Dimensionamento do complexo agroindustrial dos estados brasileiros: geração de renda, empregos e impostos. Geosul, 34, 18-39. https://doi.org/10.5007/1982-5153.2019v34n71p18.

Sesso Filho, U. A., Borges, L. T., Pompermayer Sesso, P., Alves Brene, P. R., \& Domenes Zapparoli, I (2019b). Geração de renda, emprego e emissões atmosféricas no agronegócio: um estudo para quarenta países. Revista de Economia e Agronegócio, 17(1), 30-55. https:// doi.org/10.25070/rea.v17i1.7902.

Sesso Filho, U. A., Guilhoto, J. J. M., Rodrigues, R. L., Moretto, A. C., \& Gomes, M. R. (2011). Geração de renda, emprego e impostos no agronegócio dos estados da Região Sul e restante do Brasil. Economia \& tecnologia (UFPR), 25, 71-80. Recuperado em 18 de janeiro de 2018, de http://www.economiaetecnologia.ufpr.br/revista/25\%20Capa/Umberto\%20Antonio\%20 Sesso\%20Filho\%20-\%20Joaquim\%20Jose\%20Martins\%20Guilhoto\%20-\%20Rossana\%20 Lott\%20Rodrigues.pdf

Silva, A. F., Barros, G. S. C., Fachinello, A. L., \& Castro, N. R. (2015). Perfil do agronegócio paulista e sua participação em âmbito nacional. Revista de Política Agrícola, 24(4), 97-113. Recuperado em 14 de outubro de 2020, de https://seer.sede.embrapa.br/index.php/RPA/ article/view/1059 
Srinivas, S., \& Vieira Filho, J. E. R. (2015). Farm versus firm in economic development: the assumptions and consequences of learning dynamics in agriculture and manufacturing. Texto para Discussão (IPEA), 1, 1-37. Recuperado em 16 de outubro de 2020, de https://www.ipea.gov.br/portal/images/ stories/PDFs/TDs/ingles/dp_207.pdf.

United Nations Development Programme - UNDP. (2019). Recuperado em 12 de dezembro de 2019, de http://hdr.undp.org/en/data

Yan, B., Fan, J., \& Zhou, Y. (2011). Study on the relationship between economic growth and structural change of agribusiness: evidences from national and provincial levels. Recuperado em: 09 de janeiro de 2019, de https://www.iioa.org/conferences/19th/papers/files/442_20110407041_ StudyontheRelationshipbetweenEconomicGrowthandStructuralChangeofAgribusiness.doc 